\title{
Collaborative and Social Learning Using Virtual Worlds: Preparing Students for Virtually Anything
}

\author{
http://dx.doi.org/ijac.v4i3.1734 \\ Kai Erenli and Gerhard Ortner \\ University of Applied Sciences bfi Vienna, Vienna, Austria
}

\begin{abstract}
Teams, increasingly more than individuals, are charged with the most challenging and mission-critical projects. Leaders need to evaluate and motivate from a distance. And the makeup of teams is increasingly complex - they're bigger, more diverse, more geographically distributed, composed more of specialists than generalists, and much more dependent on technology than in the past. And difficult economic times only accent these challenges." This statement made by Reeves and Read in their Book "Total Engagement" perfectly summarizes the challenge we as University of Applied Sciences and especially our degree program "Project Management and Information Technology" face while preparing students for their work life. While the use of e-mail and video-conferencing systems substantially supports the members of ever more globalized project teams, we have witnessed that the developments regarding Virtual Worlds and Communities may have a big impact on project management in the future. The paper shows what approach was chosen to take the skills already adopted by the "virtual natives" e.g. our students, what tasks were given to them to improve those skills and what lessons learned were made by the teaching stuff.
\end{abstract}

Index Terms - collaboration, decentralized teams, project management, student projects, virtual worlds

\section{INTRODUCTION}

"Teams, increasingly more than individuals, are charged with the most challenging and mission-critical projects. Leaders need to evaluate and motivate from a distance. And the makeup of teams is increasingly complex - they're bigger, more diverse, more geographically distributed, composed more of specialists than generalists, and much more dependent on technology than in the past. And difficult economic times only accent these challenges." [1] This statement perfectly summarizes the challenge we as University of Applied Sciences and especially our degree program "Project Management and Information Technology" face while preparing students for their work life. While the use of e-mail and video-conferencing systems substantially supports the members of ever more globalized project teams, we have witnessed that the developments regarding Virtual Worlds and Communities may have a big impact on project management. Therefore we have analyzed and evaluated this impact within a project called "PMIT+" with a special focus on the practicability of new tools and applications. Since many work packages were realized by students we have - as a byproduct - also evaluated the use of the Virtual Worlds as possible e-learning tools within the curriculum. The outcome of this evaluation will be presented in this paper.

\section{IDEA AND TASK}

The reasons to use Virtual Worlds as educational tools are various. From our point of view at least three important ones must be mentioned:

1. Commitment to use. Research shows that young people grow up with the use of Virtual Worlds (e.g. see [2]). Therefore the commitment to use Virtual Worlds in their everyday life and in different situations e.g. for educational purposes must be accounted for.

2. Appealing Virtualization. The state-of-the-art technology provides users with attractive and easy-to-use applications and appealing virtualizations. This also increases commitment and therefore the motivation to use the Virtual World.

3. Fun. Most Virtual Worlds have been "Massively Multiplayer Online Role-Playing Games" (MMORPG) by definition and have been very popular for generations. The evolution of Virtual Worlds into Social Virtual Worlds [3] began with Linden Lab's Second Life entering the field and has proceeded to many Virtual Worlds for working professionals. The use of moving Avatars and the "Uncanny Valley Effect" described by Mori [4] increase the fun factor during the learning process as well as acceptance for gathering knowledge rather than experience points (normally gained in MMORPGs).

The task of the "PMIT+" project was to "find a Virtual World that can be used as a main collaboration tool for project work. Use the tool extensively within the "PMIT+" project and evaluate the tool during the project". Then operate and control a small project using the tool. Several phases where implemented to reach the mission statements:

1. work on a simple definition for the concept "Virtual World",

2. compile a long list of Virtual Worlds,

3. prepare a criteria catalogue,

4. select a Virtual World to use during the project,

5. document findings and lessons learned and

6. deploy the student project as test case. 


\section{A. Definition of "Virtual World"}

As mentioned before, the first task was to find a suitable Virtual World. Therefore, it was necessary to define the term "Virtual World" in order to separate Virtual Worlds from "classic" collaboration tools, which are often inaccurately defined as "tools for virtual teams" and cause misunderstandings for the potential user. On the other hand, most of the tools established by Web 2.0 can be seen as virtual tools. In order to separate Virtual Worlds from these social networking websites/tools and elearning tools, we defined measurement categories for Virtual Worlds [5]:

1. coded,

2. ability to communicate with others (through voice or chat),

3. 2-D or 3-D visualized reality,

4. persistency,

5. run in real-time,

6. client- or browser-based.

All factors had to be fulfilled cumulatively.

\section{B. Long list of Virtual Worlds}

The Virtual Worlds chosen to be on the long list were:

Wonderland, Active Worlds, Entropia Universe, Gaia Online, IMVU, Kaneva, LambdaMOO, Maquari, World of Warcraft (MMORPG), EVE (MMORPG), Papermint, Second Life, There.com, Vastpark, Sloodle, Cobalt, virtualheroes, Teleplace, Vside, Twinity, Meetsee, Spiral matrix and Protosphere.

Virtual Worlds discovered during later work (e.g. OpenSim) were evaluated during the project (see II.c), and have been stored on a "Side List". They are awaiting further evaluation.

\section{Criteria Catalogue}

To provide a qualitative comparison of different Virtual Worlds, it is necessary first to determine key criteria by which to evaluate which worlds are considered relevant and which are negligible. The criteria selected were:

- administration/user groups,

- data security,

- resource sharing,

- communication/interaction tools,

- modifications/customizing,

- support (documentation, manuals, tutorials),

- costs/licensing,

- available languages,

- usability - client,

- assessment prerequisites (hardware, resources, ...),

- project management relevance,

- e-learning relevance.

\begin{tabular}{|c|c|l|}
\hline Criteria & Points & \\
\hline \multirow{3}{*}{} & 0 & no user roles \\
\cline { 2 - 3 } & 1 & no specific user roles \\
\cline { 2 - 3 } & 2 & classified rules (user, admin) \\
\cline { 2 - 3 } & 3 & $\begin{array}{l}\text { classified rules (user, admin, co- } \\
\text { admin) }\end{array}$ \\
\cline { 2 - 3 } & 4 & individual user roles can be defined \\
\cline { 2 - 3 } & 5 & group-based rights \\
\hline
\end{tabular}

Figure 1. Example of the Category Administration Features
Each of these categories was assessed by giving it 0 to 5 points representing the performance level of the related Virtual World.

The Top 10 of all Virtual Worlds evaluated are:

1. Teleplace (Qwaq)

2. Protosphere

3. Wonderland 0.4

4. Active World

5. Cobalt

6. Meetsee

7. World of Warcraft

8. There.com

9. IMVU

10. Kaneva

Virtual Worlds that did not meet minimal requirements (knockout criteria) had to be excluded from the evaluation. Knockout criteria were e.g.:

- most MMORPGs failed because of the lack of project management or e-learning relevance, but were tested initially to observe the fun factor and evaluate the criteria catalogue itself;

- resource sharing was limited to ftp transfers;

- many MMORPGs require a state-of-the-art graphic hardware which cannot be found in most student/office notebooks.

Worlds which were eligible but still under strong development, e.g. Wonderland, were put "on hold". Therefore the evaluation performed can only be regarded as a "snap shot". Each Virtual World has to be reevaluated when a new version is deployed.

\section{Selection of the Virtual World used}

Wonderland and Teleplace were put on the shortlist. Since Wonderland was awaiting a major release update (0.4 to 0.5$)$, Teleplace was selected to be used in the $\mathrm{PMIT}+$ project.

\section{E. Project Management Approach}

The study program "Project Management \& IT" is not affiliated with any of the Project Management methods established worldwide. Therefore the students could decide on their own which method to choose. The team decided to use the method established by the IPMA (International Project Management Association) which is also very popular in Austria.

\section{DOING PROJECTS IN A VIRTUAL ENVIRONMENT}

The following findings document the most important issues that were observed during the project. They can be seen as work in progress, since the observation is an ongoing process in current projects, which are also deployed in virtual worlds. The demonstrations of the findings are in chronological order and are all related to the PMIT+ project.

\section{A. Technical Issues \& Team Building}

Due to a lack of preparation the first meeting in a virtual meeting room ended in disaster. Neither the project manager nor the project team had tried the virtual meeting room beforehand, so the meeting had to be classified as "trial \& error". Problems encountered were:

- team members could not hear/talk to each other, 
- communication was very chaotic due to a lack of communication rules,

- open microphones with a lot of background noise,

- lag issues (network),

- poor avatar controlling skills,

- poor moderation skills of the project manager.

The meeting was aborted after 30 minutes and its subsequent improvement was given as task to the project manager. The meeting was evaluated by the project team and a follow-up meeting scheduled. As preparation each team member was asked to log into the virtual meeting room and to carry out four simple tasks:

1. try out voice communication with another team member using "push-to-talk",

2. give the avatar a personal touch,

3. try to upload a document onto the virtual whiteboard,

4. leave a virtual post-it on the message board stating that you have completed the task successfully.

The project team had to fulfill these tasks within one week and succeeded without needing further support. As a side task the project team had to make sure that the internet connectivity could support voice chat without relays at any meeting.

The project manager established the communication rules for the next meeting, which stated that the project manager would give the right to speak to individual project team members based on requests for permission to communicate made to him beforehand (via text chat). This rule was adopted from common "raid rules" of MMORPG, which were well known to at least half of the project team. The "raid rules" ensure that only necessary communication takes place during an encounter in an MMORPG. As a direct result, the next project meeting demonstrated the advanced skill level of the project team, which can be summarized as follows:

- focused conversation on topics,

- short meeting time related to the topics scheduled,

- high motivation of project team members,

- committing the project team to a "no-one-gets-leftbehind-rule"

- increased commitment to the tool used on the part of critical project team members.

The project team decided to use the virtual meeting room as a:

- document repository,

- relay chat,

- newsroom,

- think tank,

- collaboration space, and

- meeting room.

Project team members accessed the virtual room from various locations since all of them were in-service students who also had to do their regular jobs, many with a lot of travel duties. During the initial phase of the project much communication had to be done using the voice-chat tool of the virtual world. Project team members experienced bad sound quality and huge time lags while talking to each other, which impeded the progress of the project. The reason for these issues was recognized in the fact that the voice chat was operated by the provider over their own servers located in the U.S. A quick solution had to be found to maintain the high team motivation and to proceed in the communication process. The project manager suggested the use of "Team Speak", also used by players of MMORPGS. Again a majority of the team members were already familiar with the software, which helped to solve this issue with as little time loss as possible. The software was installed on a university server and has been available since then.

The following monthly meetings took place in the virtual meeting room to become more familiar with the tool and to evaluate different aspects of the software. It was interesting to see that the project team went through the team phases described by Tuckman [6] (Figure 2) just like a real-world team, even though they were in personal contact only irregularly.

Figure 3 helps to illustrate how the different stages were developed by the student project team. The size of each circle indicates how crucial these stages were to the group.

Since team motivation was very high at the beginning, the "forming" stage was crucial. Testing and Orientation during this stage were not only important for the team, they were essential for reaching the following stages at all. As a result of the distinct "forming" stage, the "storming" stage was observed as insignificant. The group did not develop any resistance to group influence and task requirements. This fact can be explained by the crucial "forming" stage. Many emotional response reactions could be observed during this stage, which helped to

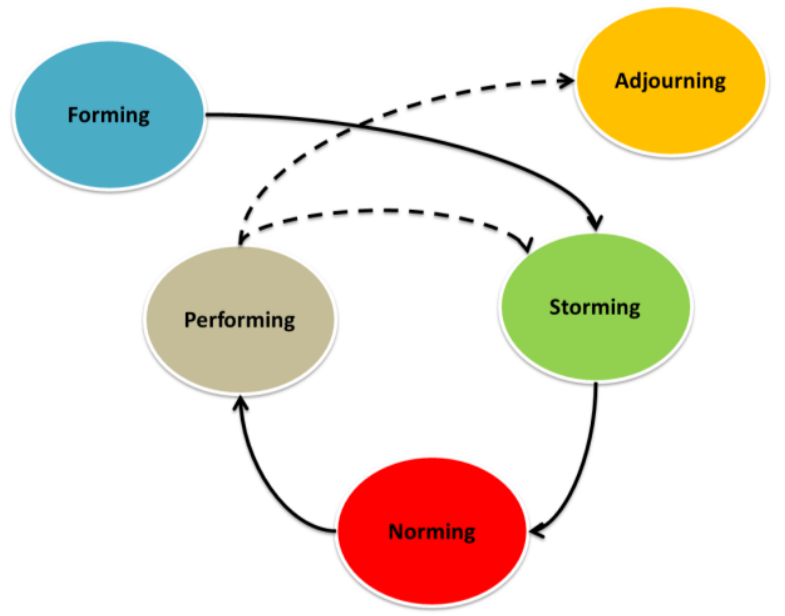

Figure 2. The stages of group development by Tuckman

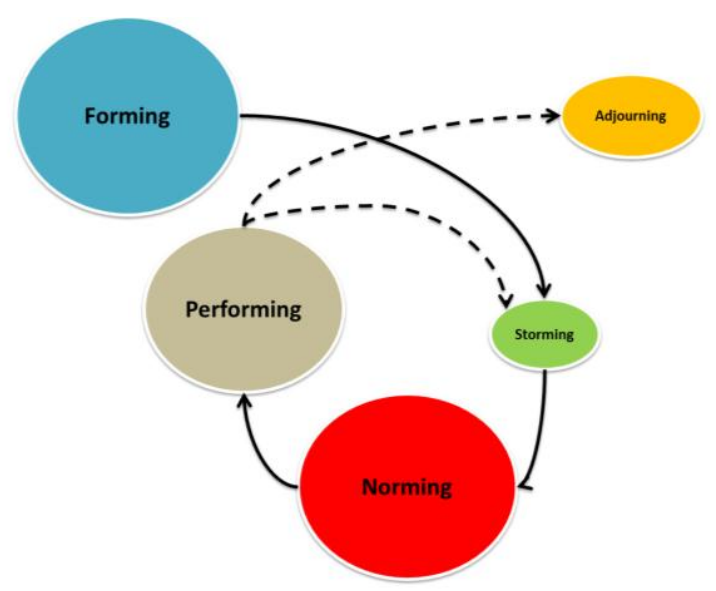

Figure 3. The stages of group development in the project team 
strengthen the team spirit once they were overcome. The use of avatars in the virtual room helped to absorb the emotional distress that occurred when the first meeting had to be aborted. The fact that some users of the project team were new to the use of virtual rooms and therefore in desperate need of support was respected by the more project team members more familiar with the virtual world.

The "norming" stage was assessed to be the most important. During this stage new standards evolved and new roles were adopted. The "no-one-gets-left-behind-rule" was deployed successfully by the team and helped to maintain a high level of motivation to work for achieving the team's goals. It also guaranteed that none of the team members went into a phase of isolation. The possibility of a team member losing his or her motivation due to an inability to gain "project speed" was highly evident during this stage.

Therefore the "performing" stage was easy to achieve for the project team. Each team member was given the assignment to prepare a virtual meeting on his or her own in monthly intervals. This approach ensured that each team member had the necessary knowledge to fulfill this task and also resulted in the fact that the usability of the software was evaluated at different user skill levels.

\section{B. Time matters}

One of the problems to be encountered with many virtual student project teams, thus also with the PMIT+-team was the scheduling of project meetings. Some of the team members had very limited time slots in which they were able to attend meetings. Delays seemed inevitable, so a solution had to be developed. The project team decided to find out each team member's preferences regarding the work packages. To this end, the work packages were presented in a short video in the virtual meeting room. Each team member could communicate their preference on the virtual whiteboard next to the presentation video within a week. Hereafter the team members were assigned a work package each, and short work package meetings were much easier to arrange because only the time slots of a few team members had to be synchronized. Short conclusio: The virtual meeting room helped to solve the time problem easily while aiding everyone to get the "big project picture" [7] through visual communication techniques.

\section{Battling the Release vs Short List - War}

Since - as described in Section I d - there is no standard software for virtual team meetings yet, the inclination was strong to switch to another virtual world software as soon as a technical feature did not fit the demands of the project team or a software bug occurred. The rule "Never change a running system" was a good rule as long as the software was running smoothly. As we have mentioned, the first problems emerged during the first virtual project meeting. As early as at this stage a discussion started whether to stick to the software selected from the shortlist or switch to a new one which had just been released. The discussion was detrimental to the project since some of the team members refused to continue work on the project in the previously selected world and decided to migrate all repository data to the brand-new software. This fact was extremely challenging for the project manager, who had to secure project continuity as well as the integrity of the project team. To end this discussion in a time-effective manner, it was decided to stick to the software selected from the shortlist during the project and start a new list on the side. A new working package called "Virtual Meetings Beyond (VMB)" was established and the once "renegade" team members were assigned to this work package. This decision helped to maintain team spirit since the team members in favor of a software switch could apply their motivation to the new task. Furthermore it helped to outline the priority of the project to the whole team. Possible "product bashing" was stopped at the end of this phase and was never again witnessed during the project.

Another reason to stick to the previously selected software was the fact that the project team was tied to a limited budget. Therefore the project team members assigned to VMB also had to do a cost-benefit analysis based on a criteria catalogue developed by the whole team.

\section{Doing the "double loop"}

Argyris described the effect of "double loop learning in organizations" back in 1977 [9]. Argyris stated that a group of individuals, such as a project team, will question the values, assumptions and policies that have led to their actions in the first place; if they are able to view and modify those, then second-order or double-loop learning has taken place. The process is demonstrated by Figure 4 .

Essential and effective communication is the key factor in project management, so the researchers who accompanied the project team decided to apply the double-loop learning process to the team. Since Argyris proposed that the best way to generate double-loop learning is a topdown approach [8], the situation was ideal. The essential question after the decision to apply the process had been taken was when to apply it.

Malus gave us the answer [9] in his research about the integration of Enriched Reflective Interventions in eLearning Projects, where he states that the Free Cash Flow is one of the fundamentals of measuring the increase in a company's liquidity. Given that the steady increase of a company's liquidity is influenced by positive paybacks from the calculated Business Cases of a project, applying the double-loop learning process may have a substantial impact. Looking at the different stages of the project team and keeping the idea of Free Cash flow as KPI in mind, we decided to implement the process after the "performing" stage. In the PMIT+ project, changes were made regarding the IT support processes, the communication rules and the project marketing activities. For instance, the need for IT support was communicated to the project manager in order to document problems encountered properly. This resulted in a capacity overload and furthermore in a time delay of the project. After the double-loop learning process the project team members were instructed to request IT support directly from the IT Department and to document the issue in a specific document in the repository.

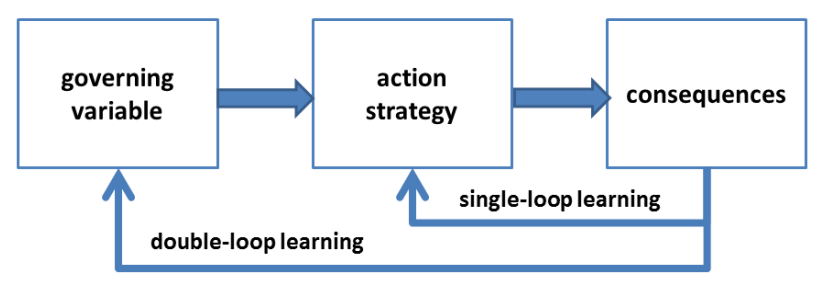

Figure 4. The double-loop learning process 
Furthermore they were asked to rate the problem on a scale from 1 to 10 . Knowledge how to rate a problem had already been gained by the project team, since all of them knew how to use Second-Level Support. If a problem occurred that was above 7 , the project manager had to look at the problem himself; every problem rated 6 or lower could be ignored by him. Similar actions were applied to the other problems encountered. As a result, the delays in the project became fewer, thus increasing project team performance and the quality of the results.

Regarding the influence of the double-loop learning process on the team building stages the following effect could be recognized. The team did not have to go through the "forming" and "storming" stages but could continue with the "norming" and "performing" stages. In this cycle the "performing" stage was also assessed to have increased (Figure 5).

Applying the double-loop learning process must be seen as an incentive to potential providers of e-learning. It neither was nor is limited to the PMIT+ project, of course, but was helpful to reach the project goals, since every motivation factor was welcomed and essential to the use of virtual worlds as an educational tool (as stated in I). Furthermore, the provider of the e-Learning environment, e.g. the university, must see the value and impact it has on students. Measurable data could be won with this method and used to convince the decision-makers to pursue the eLearning approach using virtual worlds.

\section{DOCUMENTATION OF THE FINDINGS - CONCLUSION}

Essential features of a Virtual World in an e-learning and/or project work setup can be summarized as follows:

- multi-dimensionality: appealing user interfaces increase user acceptance and the fun factor, which secures user motivation;

- real time: user activities correlate with the perspective image without time lag;

- interactivity: real interaction possible (changing objects, handling documents, ...);

- multi-user effect: interaction with other users possible (chat, voice chat, etc.);

- multi-sensoriness: several senses are appealed to;

- availability: anywhere, anytime;

- collaboration features: sharing and versioning of documents

Pure community platforms (such as e.g. StudiVz, Facebook or XING) are not considered Virtual Worlds since in particular the features of multi-dimensionality and multisensoriness are insufficiently developed. The collaboration aspects are also not represented usefully.

While Teleplace or Protosphere already represent a professional Virtual World for different kinds of usage, its costs and licensing policy are geared towards large companies (long-term agreement, higher investments) rather than educational institutions or small projects (see also [10]). And the possibility to customize the world is limited. Since many Virtual Worlds are still under heavy development, the study has to be seen as work in progress even though the project is finished. In addition the use of virtual rooms for project meetings is not yet state-of-theart for project managers and therefore leads to a skeptical approach by many of them, even slight technical problems may be hazardous to the whole project. If efficient com-

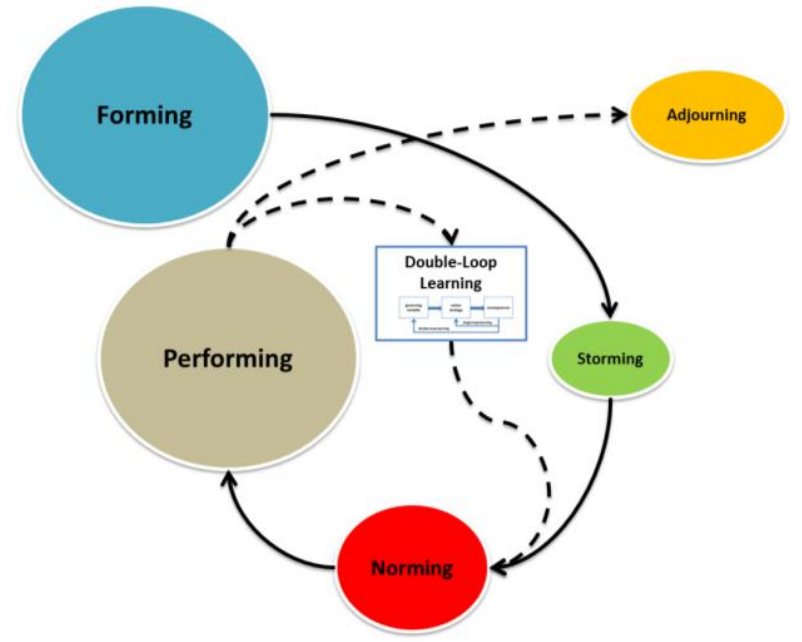

Figure 5. The double-loop learning process with regard to the team building stages

munication cannot be established in the first place, this will significantly weaken the results of the project team

Setting up Virtual Worlds in an e-learning or project management environment must be seen as a long-term investment. Especially installation \& customization require a lot of time and know-how. Using Virtual Worlds to run student projects can help to learn how to work collaboratively on decentralized teams (e.g. together with students abroad) and therefore prepares them for future work life. As mentioned, results show that much development still has to be done by software providers. Nevertheless, a checklist was compiled to assist decision-makers who want to implement a Virtual World for educational purposes today.

Some Virtual Worlds, like Open Wonderland, have to be considered as Virtual Worlds with high potential for immersive learning purposes (see also [11]). They can already be used for coding training in order to achieve two goals: students are advancing their coding/IT skills while improving the Virtual World itself (see also [12]).

\section{A. Check List for the Implementation of Virtual Worlds}

\section{Concerning the provider:}

$\square$ The provider of the virtual world makes helpful documentation available.

$\square$ The provider of the virtual world makes an "elearning" video available online (as introductory tutorial), which can be used to train staff/team members.

$\square$ Personal customer contact is offered for individual questions.

$\square$ Customizing (designing the virtual environment as autonomously as possible) is available.

$\square$ If needed, the provider of the virtual world makes a secure server available for virtual world operation or grants the possibility to install the virtual world on a separate server.

$\square$ The virtual world is designed to be integrated in an actual work environment (in contrast to a "leisure time environment" or gaming world environment). 


\section{Concerning hardware and net infrastructure:}

$\square$ The available hardware fulfils all requirements of the virtual world for optimal utilization (graphics card, memory, etc.).

$\square$ Headsets are available for online communication. Laptop microphones that are integrated next to the keyboard cause much noise, e.g. from possible typing, at the receiver's end. Push-to-talk solutions are recommended (conversation-irrelevant and/or background noise can thus be minimized).

$\square$ Stable high-speed Internet connection (high data volumes are possible during use).

$\checkmark$ The virtual world must be reachable and available worldwide (login possibility only in the company network inevitably leads to failure).

Concerning the software:

$\square$ The available operating system (incl. all software components) fulfils the requirements of the virtual world for optimal utilization.

$\square$ All project team members use the same version of the virtual world.

$\square$ Interfaces are available for the integration of third-party applications.

\section{Concerning file sharing:}

$\square$ The chosen virtual world supports all document formats in use in the project.

$\square$ Documents cannot only be displayed online, but also worked on together (ticket system is recommended to prevent version overlap).

$\square$ Documents that have been changed are available in the latest version for all project team members.

\section{Concerning data security and confidentiality:}

$\square$ Unique authentication is assured.

$\square$ Only authenticated project team members can enter the project-related virtual environment (optionally a "guest status" should be possible).

$\square$ Files that are uploaded to the virtual world for joint use can only be seen by the project team members.

$\square$ The available group administration allows for the group administrator to assign different rights (reading, writing, etc.).

$\square$ Protection against unauthorized use or abuse must exist (requires know-how).

\section{Concerning language:}

$\square$ The special characters of the choosen language are supported.

$\square$ Language etiquette must be communicated clearly (e.g. chat or oral communication has to take place in English).
Concerning the students:

$\square$ Before the actual project start, all team members have the opportunity to familiarize themselves with the virtual world.

$\square$ The project team can design its avatars individually (this increases identification with the virtual work environment).

$\square$ The project team members are not averse to working at the computer and look forward to new challenges.

$\square$ The team members work independently and have a pronounced sense of responsibility.

Concerning the university:

$\square$ The use of Virtual Worlds is welcomed and supported by the decision-makers in the university

$\square$ The staff members are sympathetic to the use of a virtual work environment.

$\square$ Staff members who are not directly involved are informed that a virtual world is in use and can get to know the virtual world (reduction of external scepticism).

Figure 6. Checklist successful e-learning in virtual worlds

It will be interesting to see Virtual Worlds used during the PMIT+ project as well as those developed recently evolve into fully qualified e-learning environments. Virtual Worlds will definitely help teachers and students to interact, learn and practice on multiple levels in the future. Students' concerns regarding distance, diversity and time flexibility can be overcome by using Virtual Worlds and therefore help to prepare students for virtually anything.

\section{REFERENCES}

[1] Reeves B., \& Read L.J. (2009). Total Engagement. Using Games and Virtual Worlds to change the way people work and businesses compete, 132-133.

[2] Wankel, K. (2010). WoW Factor: an insider's look at the real skills developed in the virtual World of Warcraft

[3] Bainbridge, W.S. (2010)., The Warcraft Civilization: Social Science in a Virtual World; Pearce, C.(2009). Communities of Play: Emergent Cultures in Multiplayer Games and Virtual Worlds.

[4] Mori, M. (1970). Bukimi no tani [The uncanny valley]. Energy 7.

[5] Erenli, K. (2010). Virtual Persons + Virtual Goods = Real Problems, 266. In Daras P. \& Mayora O. (Eds.). UCMedia 2009, LNICST 40 (pp. 265-270). Berlin, Heidelberg, New York: Springer Press.

[6] Tuckman, B.W. (1965). Developmental sequences in small groups Psychological Bulletin, 63, 384-399. http://dx.doi.org/10.1037/ $\underline{\mathrm{h} 0022100}$

[7] Gareis, Happy Projects (2006), 140.

[8] Argyris, C. (1977). Double loop learning in organizations, Harvard business review, 115 .

[9] Malus, C., The Integration of Enriched Reflective Interventions in eLearning Projects as a Cost Saving Opportunity for Increased Liquidity, Proceedings of the ICL 2010.

[10] Freitas, S. \& Rebolledo-Mendez, G. \& Liarokapis, F. \& Magoulas, G. \& Poulovassilis A. (2009). Learning as immersive experiences: Using the four-dimensional framework for designing and evaluating immersive learning experiences in a virtual world, 70. British Journal of Educational Technology Vol 41 No 1 2010. (pp. 69$85)$. 
[11] Hendaoui, A., Limayem, M. \& Thompson, C.W. (2008). 3D social virtual worlds: research issues and challenges. IEEE Internet Computing, 12, 1, 88-92. http://dx.doi.org/10.1109/MIC.2008.1

[12] Mayer, R. E. (2001), 554. Multimedia learning. New York: Cambridge University Press.

\section{AUTHORS}

Erenli, Kai works at the University of Applied Sciences bfi Vienna, Department of Project Management \& IT, A-1020 Vienna, Austria (e-mail: kai.erenli@fh-vie.ac.at).
Ortner, Gerhard, works at the University of Applied Sciences bfi Vienna, Department of Project Management \& IT, A-1020 Vienna, Austria (e-mail: gerhard.ortner@fh-vie.ac.at).

This article is an extended version of a presentation at ICELW 2011 The International Conference on E-learning in the Workplace, held from June 8th-10th, 2011 at Columbia University, New York, NY, USA. Manuscript received 8 May 2011. Published as resubmitted by the authors August $8^{\text {th }}, 2011$. 